\title{
Chemotherapy for breast cancer during pregnancy induces vascular alterations and impaired development of placental villi: a preliminary histopathological study.
}

Alessandro Del Gobbo ( $\square$ alessandro.delgobbo@policlinico.mi.it )

Ospedale Maggiore Policlinico https://orcid.org/0000-0002-8194-3232

Giovanna Scarfone

Ospedale Maggiore Policlinico

Fedro Alessandro Peccatori

Istituto Europeo di Oncologia

Antonella Villa

Aziende Socio Sanitarie Territoriale Bergamo Ovest

Wally Ossola

Ospedale Maggiore Policlinico

Giulia Ercoli

ASST Valle Olona

Silvano Bosari

Ospedale Maggiore Policlinico

Stefano Ferrero

Ospedale Maggiore Policlinico

Francesca Laura Boggio

Ospedale Maggiore Policlinico

Elena Grossi

Aziende Socio Sanitarie Territoriale Lodi

Fulvia Milena Cribiù

Ospedale Maggiore Policlinico

Research article

Keywords:

Posted Date: November 11th, 2019

DOI: https://doi.org/10.21203/rs.2.17106/v1 
License: (c) (i) This work is licensed under a Creative Commons Attribution 4.0 International License. Read Full License 


\section{Abstract}

Breast cancer is diagnosed in approximately $1 / 3000$ pregnant women. Chemotherapy may be administered after the first trimester, with improved maternal outcome and relatively few pregnancy and offspring complications. Nonetheless, no information about the effects of different chemotherapy regimens on placenta architecture and vasculature are available. Methods To evaluate histological alterations in placentas of women affected by breast cancer and treated with chemotherapy during pregnancy, we retrospectively analyzed 23 placentas of patients affected by breast cancer and treated with chemotherapy during pregnancy and 23 control placentas of women without breast cancer and with physiological pregnancies of the same gestational age. Results All the patients had breast ductal infiltrating carcinoma, 19 of 23 cases had a G3 cancer. All patients were treated with 2-6 cycles of chemotherapy starting after 16 weeks of gestation, with different protocols. No hypertensive complications and no pre-eclampsia episodes were observed; birth weight was consistent with gestational age in all babies in both group with no uneventful outcomes and no perinatal mortality or fetal malformations. Twenty out of 23 cases (86\%) showed hypoxia-induced villous alterations, including increased syncytial knotting (Tenney-Parker changes), perivillar fibrin deposits, distal villous hypoplasia or accelerated maturation and focal villous chorangiosis. These alterations were found in 19 out of 23 controls (83\%), with no statistically significant difference between the two groups. Conclusions These results shows that chemotherapy in the second and third trimester of pregnancy may lead to non-specific alterations in placental vasculature and morphology.

\section{Background}

Cancer is detected in approximately in 1/1000 pregnant women [1], with breast cancer being the most frequent malignant tumor occurring during gestation, followed by cervical cancer, melanoma, leukemia and lymphoma [2-4]. The overall incidence of breast cancer during pregnancy varies between 2.4 to 7.3 per 100,000 [5-7], but it will become more common in the future due to the current trend of postponing pregnancy [8] and to a possible increase of incidence of breast cancer in young women $[9,10]$.

Managing breast cancer during pregnancy is demanding and deserves particular attention because of the clinical and ethical implications as potentially life-saving chemotherapy for the pregnant mother may be potentially life-threatening for the developing fetus [11].

Managing breast cancer during pregnancy is very complicated and should be personalized, including a multidisciplinary team discussion balancing possible adverse maternal and fetal health impacts [1].

While surgery may be proposed at any gestational age, endocrine treatment, targeted therapies and radiation therapy are usually postponed after delivery. Chemotherapy is contraindicated during the first trimester, but has been increasingly used with good maternal efficacy thereafter $[1,12,13]$.

For most patients managed with an appropriate treatment during pregnancy, cancer prognosis is similar to non-pregnant patients [14-16]. 
Children outcome after in utero exposure to chemotherapy has been reassuring. Available literature does not show an increased rate of fetal malformations and follow up of these babies indicates a normal neurological development [18-20]. Nonetheless patients treated with chemotherapy during pregnancy still have a higher rate of pregnancy complications, including hypertensive disorders, preterm deliveries and fetal growth restriction $[12,20]$.

For most patients managed with an appropriate treatment during pregnancy, cancer prognosis is similar to non-pregnant patients [14-16].

Chemotherapy drug intake in the $1^{\text {st }}$ trimester can lead to an increased risk of spontaneous abortion, fetal death and major malformations [11], while children outcome after in utero exposure to chemotherapy in the $2^{\text {nd }}$ and $3^{\text {rd }}$ trimester has been reassuring, without an increased rate of fetal malformations and with normal neurological development, documenting an association of intrauterine growth restriction and low fetal birth weight [17-19].

The placenta is pivotal in modulating oxygen and nutrients exchange between the mother and the fetus. Remodeling of the maternal spiral arteries and increased perfusion of the intervillous placental spaces is needed for the normal development of placental vasculogenesis, while maternal diseases such as hypertension, diabetes or infections are related to specific placental lesions, with a significant association with adverse neonatal outcome [21-25].

Whereas the effects of chemotherapy during pregnancy for mother and fetus are well described, its effects on the placenta remain largely undetermined.

This is of clinical relevance, as placental alterations may induce pregnancy complications and possibly impair fetal health.

The aim of this study is to examine placental morphology of patients treated with chemotherapy for breast cancer during pregnancy trying to identify peculiar histological changes and possibly to correlate them with fetal outcome.

\section{Methods}

A total of 23 patients diagnosed with breast cancer and treated with chemotherapy during pregnancy that gave birth at Clinica Mangiagalli, Fondazione IRCCS Ca' Granda - Ospedale Italy between 2004 and 2017 (named "cases" group) and 23 patients with physiological pregnancy that gave birth in the same institution in 2018 (named "controls" group) were retrospectively analyzed.

A lot of cases were diagnosed in other hospital everywhere in Italy and referred to European Institute of Oncology (IEO) considering their experience in treatment cancer in pregnancy.

A long-standing collaboration joins IEO and Clinica Mangiagalli, where patients with cancer in pregnancy may to undergo chemotherapy and have an excellent team for fetal and neonatal well-being monitoring. 
Exclusion criteria for all controls were: maternal medical disorders (Crohn's Disease, colitis, congenital heart disorders, auto-immune disease), obstetrical complication including hypertensive disorders, diabetes, preterm labor, maternal infection,cholestasis and fetal growth restriction.

Recorded patients characteristics included maternal age, ethnicity, maternal body mass index, cigarettes smoking during pregnancy, obstetrical complication, gestation age (GA) at birth and birth weight.

We obtained a written informed consent for the treatment with chemotherapy.

Tissue slides were collected and retrieved from the archives of the Division of Pathology of the same institution.

Gross examination of the placentas included weight (recorded immediately after delivery) and diameter (3 dimensions), completeness of maternal decidual side and membranes with color, cord inserction and length, umbilical coiling index, number of umbilical cord vessels and relevant abnormal findings.

Five samples for each case were analyzed the time of the diagnosis, including umbilical cord sections, amnio-chorial membranes, and peripheral, intermediate and central regions of the placental parenchyma.

All the specimen were fixed in neutral buffered $10 \%$ formalin, paraffin-embedded and were stained with haematoxylin and eosin (H\&E).

Histopathologic analysis of the placenta was performed, and slides were independently re-evaluated by two expert pathologists (FMC and ADG). If results were not consistent, the case was reviewed by a third pathologist (SF) and a consensus was made between the 3 pathologists.

Histopatological revision was performed in accordance with the recently published criteria of the Amsterdam Placental Workshop Group Consensus Statement [26] and primary cancer were diagnosed and staged according to the last AJCC TNM classification [reference0 TNM].

Data were statistically evaluated using the MedCalc® statistical package (MedCalc ${ }^{\circledR}$, Belgium). The tests were performed at the $5 \%$ significance level $(p<.05)$. Comparisons between groups were performed with the chi-squared test. P values were reported when $<.05$, otherwise are indicated as "n.s." (not significant).

\section{Results}

Of the 23 patients of the cases group, 23 had breast ductal infiltrating carcinoma. Nineteen of 23 cases had a poorly differentiated (G3) cancer.

Clinical characteristics of the cases are detailed in Table 1.

All patients were treated with 2-6 cycles of chemotherapy starting after 16 weeks of gestation. The combination of every three weeks Epirubicin $(75 \mathrm{mg} / \mathrm{sqm})$ and Cyclophosphamide $(750 \mathrm{mg} / \mathrm{sqm})$ was used in 12 patients, while weekly Epirubicin ( $35 \mathrm{mg} / \mathrm{sqm}$ ) was used in 11 patients. 
Possible complications were studied during pregnancy, delivery and till discharge of all patients.

None hypertensive disorders during pregnancy complications were reported in patients treated with chemotherapy during chemotherapy administrations. In particular no pre-eclampsia episodes were observed.

Birth weight was consistent with gestational age in all babies in both groups. Median gestational age at delivery was 36 weeks (range 34-38 weeks) for cases and 39 weeks (range 36-40 weeks) for controls.

No babies had uneventful outcomes and no perinatal mortality or fetal malformations were observed.

Clinical characteristics of the cases are detailed in Table 1.

We classified histological lesions according to the Amsterdam Placental Workshop Group Consensus Statement [25] in maternal vascular malperfusion of the placental bed, fetal vascular malperfusion and delayed villous maturation.

\section{Maternal vascular malperfusion of the placental bed}

Accelerated villous maturation - Twenty out of 23 cases (86\%) showed hypoxia-induced villous alterations, including increased syncytial knotting (Tenney-Parker changes), perivillar fibrin deposits, distal villous hypoplasia or accelerated maturation and focal villous chorangiosis (Figure 1). These alterations were found in 19 out of 23 controls (83\%), with no statistically significant difference between the two groups.

All cases showed a certain degree of villous agglutination, characterized by a mixture of extracellular matrix and fibrin that completely surrounds large zones of distal villi with preservation of the intervillous space.

In association, we found in $8 / 23$ cases (34\%) intravillar fibrin deposition and $8 / 23$ cases (34\%) developed intravillar calcifications; these findings were not reported in controls, with a statistically significant difference between the two grouos $(p=0.006)$. In addition, $14 / 23$ cases $(60 \%)$ and $17 / 23$ controls $(28 \%)$ showed perivillar calcification ( $p=n . s$.$) .$

Peculiar histological characteristics of this category are illustrated in Figure 2 and 3.

Fifteen out of 23 cases (65\%) and 8/23 controls (35\%) showed foci of villous immaturity, which is characterized by villi small for the gestational age with edematous stroma ( $p=n . s$.$) .$

Distal villous hypoplasia - In all cases and in 19/23 controls (83\%) we observed a marked variation in villous diameters with formation of adherent villous clusters, distal villous hypoplasia and peripheral villous hypoplasia (Figure 4) ( $p=n . s$.). The villous tree showed a decrease in the rate of distal to proximal 
stem villi. Clusters of syncytial cells surrounded knots of long, thin and non-branching immature intermediate villi. There was a decreased number of fetal arterioles and those remaining showed hypertrophy of the media.

Distal villous immaturity was seen in association with distal villous hypoplasia and it was characterized by an increased number of enlarged distal villi, stromal cells and villous macrophages. Capillaries tended to be central with a decrease in vasculosyncytial cells.

\section{Fetal vascular malperfusion}

Stem vessel obliteration - All cases and 19/23 controls (83\%) showed partial or complete stenosis associated with hypertrophy and fibrosis of the arterial wall of truncal vessels of first, second and third order with evidences of thrombosis and recanalization of these vessels in few cases ( $p=n . s$.).

Consequently, we observed fibrotic and avascular villi intermixed with normally developed villi (see later).

Thrombosis - Two out of 23 cases (8\%) and none of the controls showed fibrin deposits and lysed red blood cells arranged in parallel layers to chorial plaque ( $p=n . s$.$) .$

One out of the 23 cases (4\%) and none of the controls showed thrombosis that pushed villi to the periphery of the parenchyma; villi showed a laminated appearance and were sometimes fibrotic $(p=n . s$.$) .$

Intervillous thrombi mainly occurred in the intervillous space in central areas of the placenta. Thrombi appeared first as fresh red clots, which then became laminated thrombi and finally old white lesions, with no real organization. Intervillous thrombi contained both fetal and maternal red blood cells.

Two out of 23 cases (8\%) showed subchorial thrombosis and all cases marked thickening of the decidual and spiral arteries wall.

Avascular villi - Two or more small foci with total loss of terminal villi capillaries in association with villar fibrosis were found in all cases.

\section{Delayed villous maturation}

The presence of marked acute and chronic infiltrate between villi (intervillositis) was found focally in 1 out of 23 cases $(4 \%)$ and in $2 / 23(8 \%)$ of the controls ( $p=n . s$.).

Acute intervillositis was characterized by the presence of neutrophils in the intervillous space with occasional involvement of contiguous villi, often accompanied by patchy intervillous fibrin. On the contrary, chronic intervillositis showed a predominance of intervillous macrophages. 
A chronic villous inflammation not associated with recognizable microorganisms (non-specific villitis) was identified in the villous connectival axis in 1 out of 23 patients (4\%) but in none of the controls (p=.n.s.).

Microscopically, lymphocytes were mixed with normal villi, accompanied by fibrin deposition and villous agglutination.

Finally, 3 out of 23 cases (13\%) and 2/23 controls (8\%) showed acute choramniositis and 1 out of 23 cases $(4 \%)$ and none of the controls acute funisitis ( $p=$.n.s.).

\section{Other lesions}

One specimen displayed a parenchymal chorioangioma, characterized by abundant fibrous connective tissue associated with small, congested vascular structures surrounded by proliferative mono stratified endothelium.

As no major fetal abnormalities were present at birth, a correlation between histological alterations and fetal outcome could not be made.

No statistically significant correlation with placental macroscopic findings such as placental weight between cancer and control group was found.

\section{Discussion}

The incidence of breast cancer diagnosed during pregnancy is relatively low, but this situation remains burdened by difficult clinical decisions [1].

Studies on pregnant breast cancer patients have demonstrated that chemotherapy may be administered after the first trimester, when the risk of maternal and fetal complication is limited and pregnancy interruption is not necessary [12]. The most frequently used drugs, including anthracyclines and taxanes, are substrate of the $A B C$ proteins that are highly expressed in the placenta throughout gestation [27]. These proteins are responsible for cancer cell drug resistance, as they are able to recognize and excrete chemotherapy molecules outside cancer cells. A similar mechanism has been hypothesized for the trophoblast during pregnancy: it could preserve the fetus from chemotherapy exposure through selective pumping toward maternal compartment. Experimental evidences in pregnant baboons confirm that only a small amount of doxorubicin and paclitaxel reaches the fetal tissues [28] and clinical data in humans confirm normal development in offspring of mothers exposed to chemotherapy during gestation $[18,19]$. Nonetheless, chemotherapy administration in the second and third trimester has been associated with a slight increase in pregnancy complications, suggesting that the development of placental vascular tree might be hampered by a direct vascular toxicity induced by antineoplastic agents or that placental inflammatory changes might be involved in the pathogenesis of pregnancy complications. 
Overall placental alterations of pregnant patients undergoing chemotherapy are similar to those caused by chronic hypoxia or vascular and metabolic diseases such as hypertensive, diabetic disorders and thrombophilia (fetal thrombotic vasculopathy) [23-25].

The alterations classified according to the recently published criteria of the Society for Pediatric Pathology for classification of placental pathology [25] were present in both groups with no statistically significant differences except for the presence of intravillar calcifications and fibrin deposits, which were more frequent in the cases than controls.

Inflammatory changes were less consistent, with few cases showing chronic flogistic infiltrate in the villous cores (i.e. villitis) and in the intervillous spaces (i.e. intervillitis).

Acute inflammation, more probably due to delivery problems than to chemotherapy itself, was found in membranes and in the umbilical cord in a small percentage of cases.

Our study confirms, for the first time, that placental maternal vascular malperfursion of the placental bed, fetal vascular malperfusion and delayed villous maturations are the most important anomalies observed after chemotherapy administration while inflammatory changes of villi, umbilical cord and membranes are less represented.

\section{Conclusions}

For the first time our findings confirm that chemotherapy administrated in the second and third trimester of pregnancy may lead to non-specific alterations in placental perfusion and morphology.

These modifications may be co-causal in producing the slight fetal growth retardation or pregnancy complications previously described in literature, even if in our series all birth weight was consistent with gestational age in all babies. For this reason, the analysis of a larger sample size and the correlation of specific placental alterations with fetal outcome are needed and under evaluation.

On the contrary to other data in literature our study consider only one type of tumor (breast cancer), avoiding heterogeneity due to cancer types and chemotherapeutic agents. To our knowledge no other article have explored a so homogeneous and numeorous group of patients with breast cancer in pregnancy.

In our analysis remains heterogeneity in number of cycle administered within the "cases"group.

Considering the results of Verheecke's [29] analysis, where no fetal growth restriction had found in patients with breast cancer, it would be also interesting investigate fetal growth restriction in our cohort.

\section{Declarations}

\section{Ethics approval and consent to participate}


This work was approved by Fondazione IRCCS Ca' Granda - Ospedale Maggiore Policlinico ethics committee (ID 81456).

\section{Consent for publication}

Not applicable.

\section{Availability of data and materials}

Data sharing is not applicable to this article as no datasets were generated or analysed during the current study.

\section{Competing interests}

The authors declare that they have no competing interests.

\section{Funding}

This work was supported by the Italian Minister of Health-Ricerca Corrente program 2017 (to SF).

\section{Authors' contributions}

$A D G, F M C$ and SF analyzed the histopatological data and reviewed the cases; GS, AV, FAP, WO and EG collected, analyzed and interpreted clinical data; GE processed tissue specimens; ADG and FB drafted the manuscript; SF, SB and FMC supervised the work.

\section{References}

1. Peccatori FA, Azim HA Jr, Orecchia R, Hoekstra HJ, Pavlidis N, Kesic V, et al. Cancer, pregnancy and fertility: ESMO Clinical Practice Guidelines for diagnosis, treatment and follow-up. Ann Oncol. 2013;24 Suppl 6

2. Amant F, Loibl S, Neven P, Van Calsteren K. Breast cancer in pregnancy. 2012;379:9815.

3. Woo JC, Yu T, Hurd TC. Breast cancer in pregnancy: a literature review. Arch Surg Chic III 1960. 2003;138:1.

4. Leslie KK, Lange CA. Breast cancer and pregnancy. Obstet Gynecol Clin North Am. 2005;32:4.

5. Lee YY, Roberts CL, Dobbins T, Stavrou E, Black K, Morris J, et al. Incidence and outcomes of pregnancy-associated cancer in Australia, 1994-2008: a population-based linkage study. BJOG. 2012;119:13.

6. Eibye S, Kjær SK, Mellemkjær L. Incidence of pregnancy-associated cancer in Denmark, 1977-2006. Obstet Gynecol. 2013;122:3. 
7. Parazzini F, Franchi M, Tavani A, Negri E, Peccatori FA. Frequency of Pregnancy Related Cancer: A Population Based Linkage Study in Lombardy, Italy. Int J Gynecol Cancer. 2017;27:3.

8. Johnson J-A, Tough S, Society of Obstetricians and Gynaecologists of Canada. Delayed childbearing. J Obstet Gynaecol Can. 2012;34:1.

9. Andersson TM-L, Johansson ALV, Hsieh C-C, Cnattingius S, Lambe M. Increasing incidence of pregnancy-associated breast cancer in Sweden. Obstet Gynecol. 2009;114:3.

10. Merlo DF, Ceppi M, Filiberti R, Bocchini V, Znaor A, Gamulin M, et al. Breast cancer incidence trends in European women aged 20-39 years at diagnosis. Breast Cancer Res Treat. 2012;134:1.

11. Abellar RG, Pepperell JR, Greco D, Gundogan F, Kostadinov S, Schwartz J, Tantravahi U, De Paepe ME. Effects of chemotherapy during pregnancy on the placenta. Pediatr Dev Pathol. 2009;12:1.

12. Loibl S, Han SN, von Minckwitz G, Bontenbal M, Ring A, Giermek J, et al. Treatment of breast cancer during pregnancy: an observational study. Lancet Oncol. 2012;13:9.

13. Krishna I, Lindsay M. Breast cancer in pregnancy. Obstet Gynecol Clin North Am. 2013;40:3.

14. Azim HA, Santoro L, Russell-Edu W, Pentheroudakis G, Pavlidis N, Peccatori FA. Prognosis of pregnancy-associated breast cancer: a meta-analysis of 30 studies. Cancer Treat Rev. 2012;38:7.

15. Azim HA, Botteri E, Renne G, Dell'orto P, Rotmensz N, Gentilini O, et al. The biological features and prognosis of breast cancer diagnosed during pregnancy: a case-control study. Acta Oncol. 2012;51:5.

16. Amant F, von Minckwitz G, Han SN, Bontenbal M, Ring AE, Giermek J, et al. Prognosis of women with primary breast cancer diagnosed during pregnancy: results from an international collaborative study. J Clin Oncol. 2013;31:20.

17. Cardonick E, Dougherty R, Grana G, Gilmandyar D, Ghaffar S, Usmani A. Breast cancer during pregnancy: maternal and fetal outcomes. Cancer J Sudbury Mass. 2010;16:1.

18. Amant F, Van Calsteren K, Halaska MJ, Gziri MM, Hui W, Lagae L, et al. Long-term cognitive and cardiac outcomes after prenatal exposure to chemotherapy in children aged 18 months or older: an observational study. Lancet Oncol. 2012;13:3.

19. Amant F, Vandenbroucke T, Verheecke M, Fumagalli M, Halaska MJ, Boere I, et al. Pediatric Outcome after Maternal Cancer Diagnosed during Pregnancy. N Engl J Med. 2015;373:19.

20. Van Calsteren K, Heyns L, De Smet F, Van Eycken L, Gziri MM, Van Gemert W, et al. Cancer during pregnancy: an analysis of 215 patients emphasizing the obstetrical and the neonatal outcomes. $\mathrm{J}$ Clin Oncol. 2010;28:4.

21. Nessmann-Emmanuelli C, Sturbois G, Kone-Pale B et al. Macroscopic examination of the fresh placenta. Statistical analysis of 1,200 cases. Comparison with maternal and neonatal pathology. J Gynecol Obstet Biol Reprod 1976;3.

22. Stanek J. Hypoxic patterns of placental injury: a review. Arch Pathol Lab Med 2013;137.

23. Egbor, M.,Ansari,T.,Morris,N.,Green,C.,Sibbons,P. Maternalmedicine: morphometric placental villous and vascular abnormalities in early-and late- onset preeclampsia with and without fetal growth restriction. BJOG: An International Journal of Obstetrics \& Gynaecology 2006;113:5. 
24. Falco ML, Sivanathan J, Laoreti A, Thailaganathan B Khalil A. Placental histopathology associated with pre-eclampsia: systematic review and meta-analysis. Ultrasound Obstet Gynecol 2017;50:39.

25. Redline RW, Heller D, Keating S, Kingdom J. Placental diagnostic criteria and clinical correlation-a workshop report. Placenta 2005;26.

26. Khong TY, Mooney EE, Ariel I, Balmus NC, Boyd TK, Brundler MA, Derricott H, Evans MJ, FayePetersen OM, Gillan JE, Heazell AE, Heller DS, Jacques SM, Keating S, Kelehan P, Maes A, McKay EM, Morgan TK, Nikkels PG, Parks WT, Redline RW, Scheimberg I, Schoots MH, Sebire NJ, Timmer A, Turowski G, van der Voorn JP, van Lijnschoten I, Gordijn SJ. Sampling and Definitions of Placental Lesions: Amsterdam Placental Workshop Group Consensus Statement. Arch Pathol Lab Med. 2016;140.

27. Joshi AA, Vaidya SS, St-Pierre MV, Mikheev AM, Desino KE, Nyandege AN, Audus KL, Unadkat JD, Gerk PM Placental ABC transporters: biological impact and pharmaceutical significance. Pharm Res 2016;33.

28. Van Calsteren K, Verbesselt R, Ottevanger N, Halaska M, Heyns L, Van Bree R, de Bruijn E, Chai D, Delforge M, Noens L, Renard V, Witteveen E, Rob L, de Hoon J, Amant F. Pharmacokinetics of chemotherapeutic agents in pregnancy: a preclinical and clinical study. Acta Obstet Gynecol Scand. 2010;89:10.

29. de Haan J, Verheecke M, Van Calsteren K, Van Calster B, Shmakov RG, Mhallem, Gziri M, Halaska MJ, Fruscio R, Lok CAR, Boere IA, Zola P, Ottevanger PB, de Groot CJM, Peccatori FA, Dahl Steffensen K, Cardonick EH, Polushkina E, Rob L, Ceppi L, Sukhikh GT, Han SN, Amant F; International Network on Cancer and Infertility Pregnancy (INCIP). Oncological management and obstetric and neonatal outcomes for women diagnosed with cancer during pregnancy: a 20-year international cohort study of 1170 patients. Lancet Oncol. 2018;19:3.

\section{Table}

\section{TABLE 1 - Clinicopatholgical characteristics of the series}




\begin{tabular}{|c|c|c|c|c|c|c|c|}
\hline & N. & Age & Histotype & Grade & Stage & $\begin{array}{l}\text { Gestational age at } \\
\text { delivery (weeks) }\end{array}$ & Chemotherapy \\
\hline Cases & 23 & $\begin{array}{c}36(30- \\
43)\end{array}$ & $\begin{array}{c}23 / 23(100 \%) \\
\text { Ductal }\end{array}$ & $\begin{array}{c}4 / 23(17 \%) \\
\text { G2 } \\
19 / 23 \\
\text { (83\%) G3 }\end{array}$ & $\begin{array}{c}4 / 23 \\
(17 \%) \text { IA } \\
7 / 23 \\
(30 \%) \text { IIA } \\
4 / 23 \\
(17 \%) \text { IIB } \\
1 / 23 \text { (5\%) } \\
\text { IIC } \\
3 / 23 \\
(14 \%) \text { III } \\
4 / 23 \\
(17 \%) \text { IV }\end{array}$ & $36(34-38)$ & $\begin{array}{c}\text { 13/23 (57\%) } \\
\text { EPI+CYC } \\
10 / 23(43 \%) \\
\text { WEPI }\end{array}$ \\
\hline Controls & 23 & $\begin{array}{c}36(30- \\
45)\end{array}$ & -- & -- & -- & $36(34-38)$ & -- \\
\hline
\end{tabular}

Clinicopathological data of patients treated with chemotherapy during pregnancy and controls, including primary breast cancer pathological details and chemotherapy regimens used during pregnancy ( $\mathrm{PI}=$ epirubicin; $\mathrm{CYC}=$ cyclophosphamide; $\mathrm{wEPI}=$ weekly epirubicin).

\section{Figures}




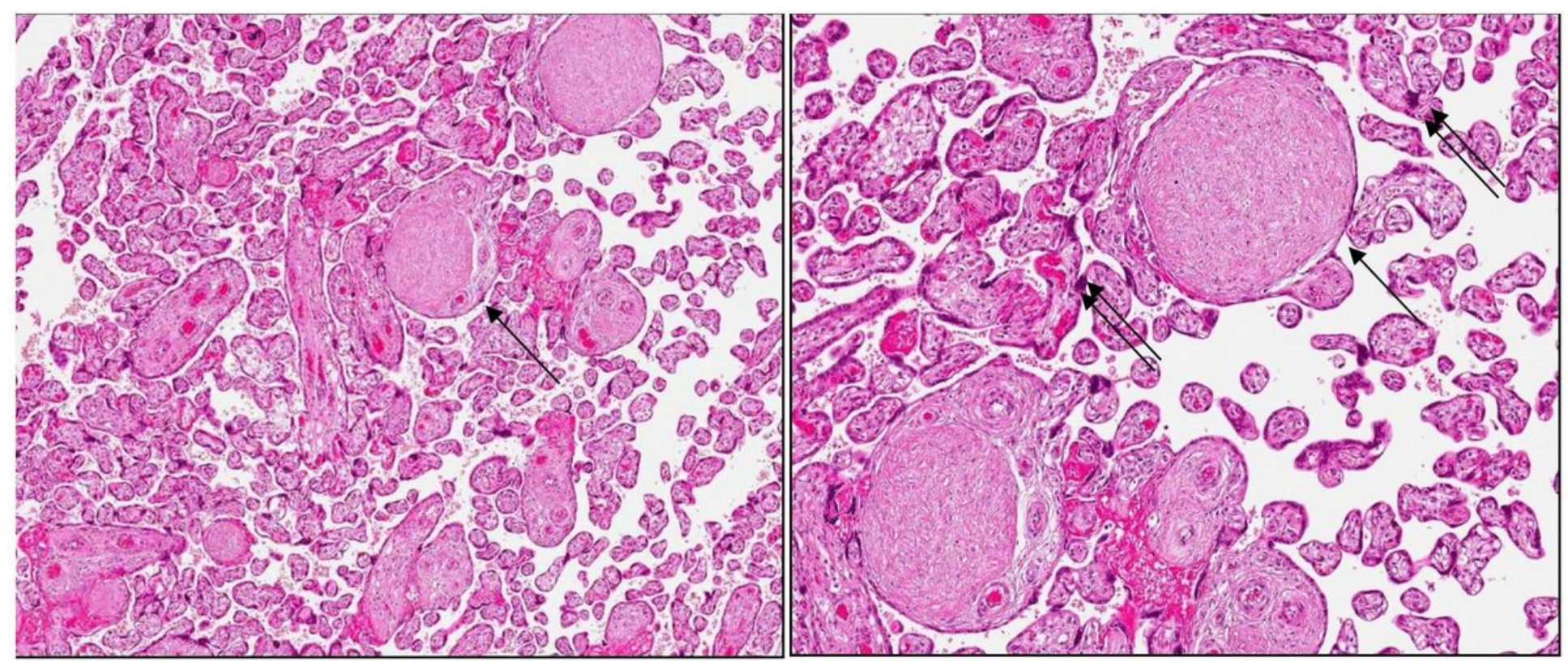

\section{Figure 1}

Terminal villi deficiency with distal villous hypoplasia, characterized by an increased number of enlarged distal villi (single arrow) in association with hypoxia-induced villous alterations including increased syncytial knotting (double arrow) (H\&E 4x and 10x, representative slides from case \#5, ductal G3 carcinoma in 30 years old woman treated with wEPI who delivered at 36 weeks). 


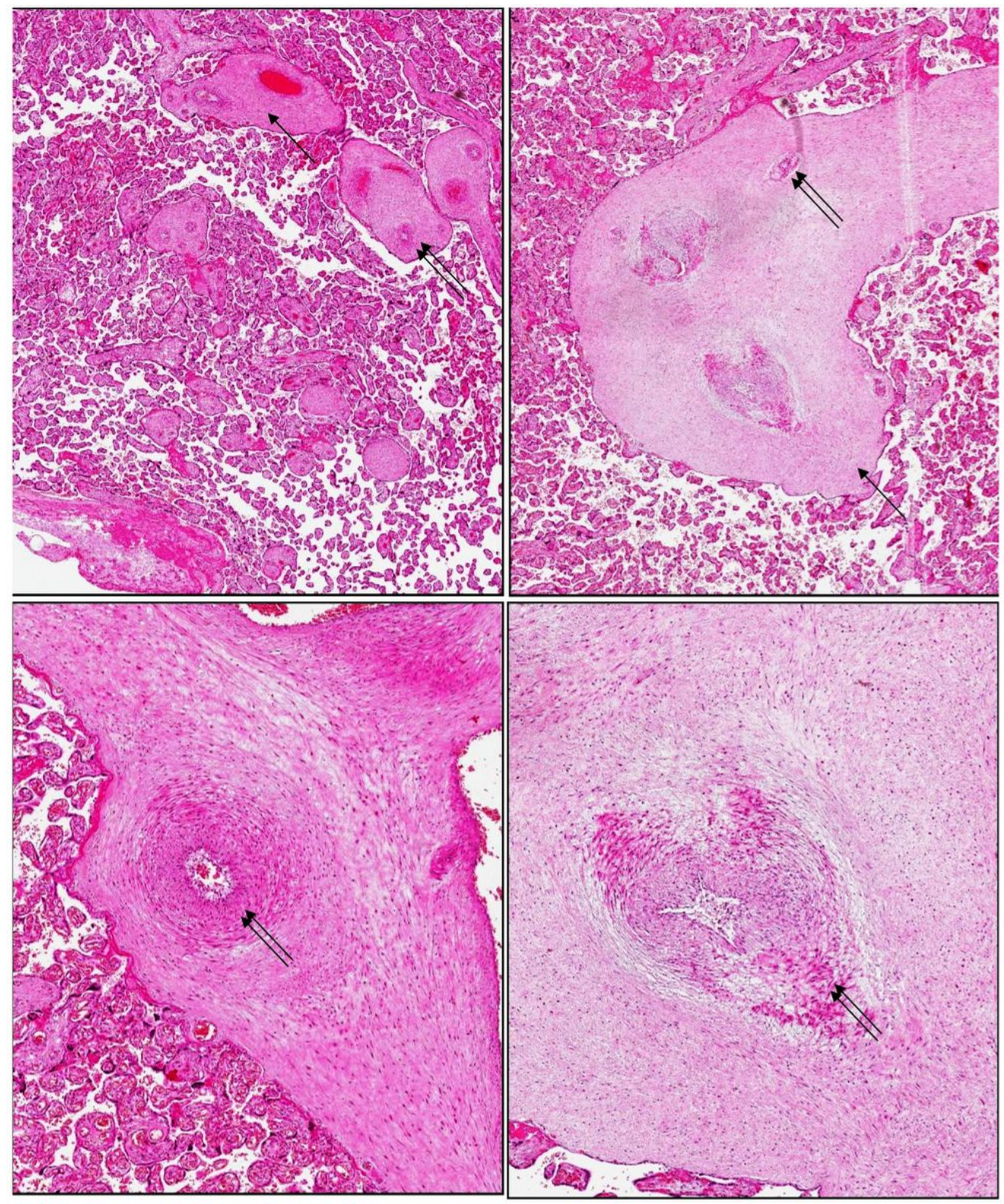

\section{Figure 2}

Stenosis more or less complete with hypertrophy and fibrosis of the arterial wall of truncal vessels of first, second and third order (single arrow) with, sometimes, images of thrombosis and recanalization of these vessels (double arrow) (from upper left to lower right: H\&E 2x, 4x, 10x and 10x, representative slides from case \#9, ductal G3 carcinoma in 31 years old woman treated with EPI+CYC who delivered at 38 weeks). 

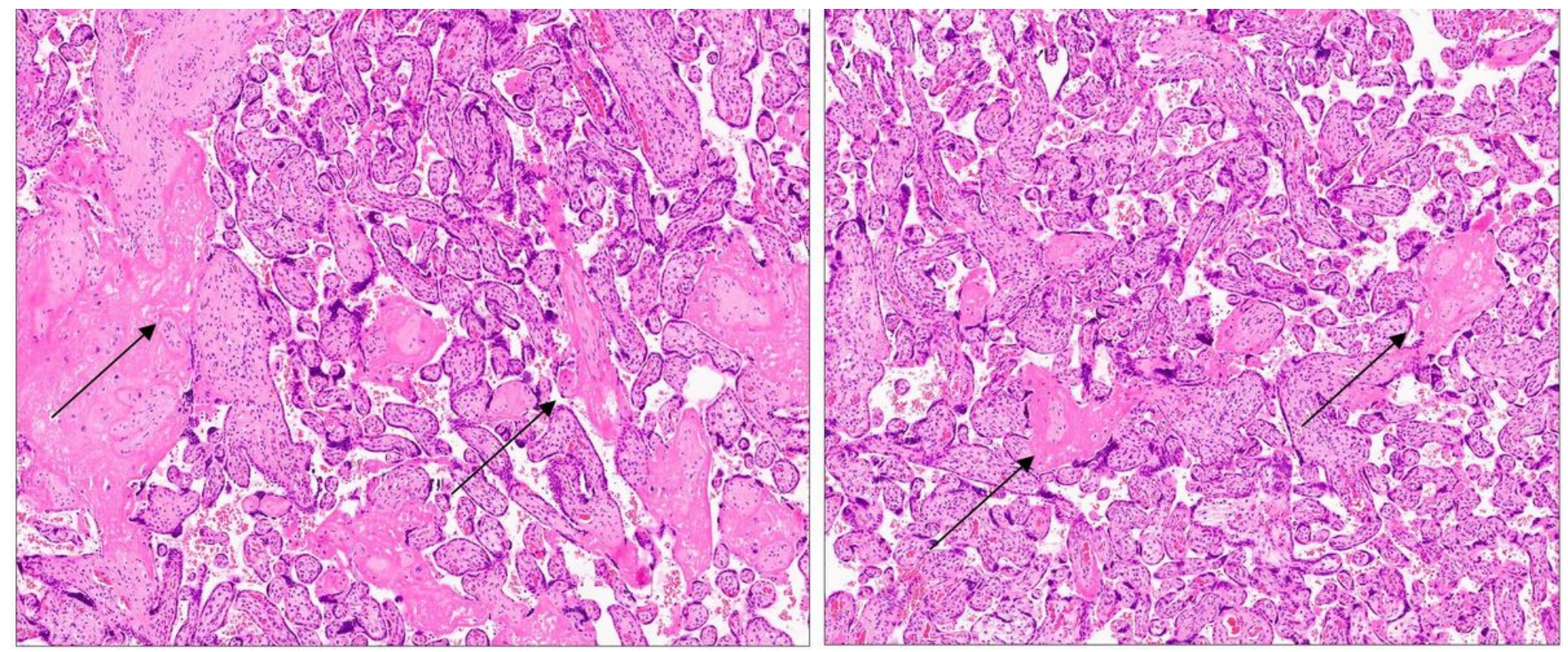

\section{Figure 3}

Perivillar fibrin deposits in a case (left) and a control patient (right), with eosinophilic amorphous material surrounding villi and filling intervillous space (H\&E 4x, representative slides from case \#20, ductal G3 carcinoma in 40 years old woman treated with wEPI who delivered at 35 weeks and from a control placenta of a 35 years old woman who delivered at 35 weeks).
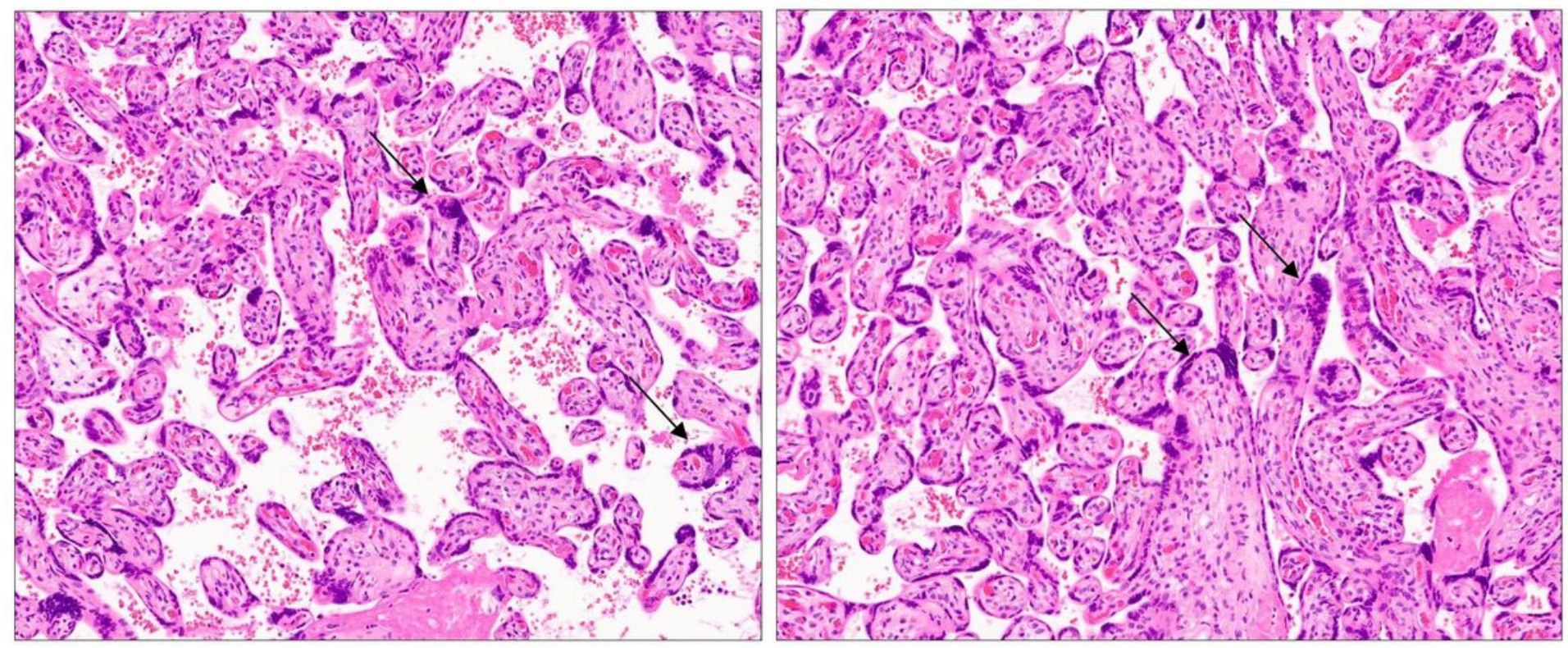

\section{Figure 4}

Details of hypoxia-induced villous alterations including increased syncytial knotting in a case (left) and a control patient (right) (H\&E 10x, representative slides from case \#3, ductal G3 carcinoma in 36 years old woman treated with $\mathrm{EPI}+\mathrm{CYC}$ who delivered at 36 weeks and from a control placenta of a 34 years old woman who delivered at 35 weeks). 